ISSN 0103-5150

Fisioter. Mov., Curitiba, v. 25, n. 3, p. 617-627, jul./set. 2012

Licenciado sob uma Licença Creative Commons

\title{
Repercussões morfológicas e funcionais do exercício sobre a regeneração nervosa periférica
}

\author{
Morphological and functional repercussion on \\ peripheral nerve regeneration after exercises
}

\section{Fernanda Possamai ${ }^{[a]}$, Daniela Regina Pacheco ${ }^{[\mathrm{b}]}$, Tiago Souza dos Santos ${ }^{[c]}$, Edison Sanfelice André ${ }^{[d]}$}

[a] Mestranda em Ciências Fisiológicas pela Universidade Federal de Santa Catarina (UFSC), Florianópolis, SC - Brasil, e-mail: fpossamai@gmail.com

[b] Graduada em Fisioterapia pela Universidade Regional de Blumenau (FURB), Florianópolis, SC - Brasil, e-mail: dany.pacheco@brturbo.com.br

[c] Doutorando em Neurociências pela Universidade Federal de Santa Catarina (UFSC), Florianópolis, SC - Brasil, e-mail: santos.ts@hotmail.com.

[d] Doutor em Neurociências pela Universidade Federal de São Paulo (UNIFESP), professor titular da Universidade Regional de Blumenau (FURB), professor associado ao Programa Multicêntrico em Ciências Fisiológicas (PMPGFis) da Universidade Federal de Santa Catarina (UFSC), Florianópolis, SC - Brasil, e-mail: sanfelice@furb.br

\section{Resumo}

Introdução: A indicação de exercícios físicos como abordagem terapêutica após lesões nervosas periféricas, apesar de resultados clínicos favoráveis, ainda não é consenso na literatura pertinente. Objetivos: Este estudo buscou avaliar a interferência do exercício em roda motorizada no processo de regeneração nervosa periférica. Materiais e métodos: Foram utilizados 48 ratos Wistar divididos proporcionalmente em quatro grupos de 12 ratos cada (seis controles e seis experimentais). Após treinamento, os ratos foram submetidos à axonotmese do nervo ciático direito. Todos os grupos iniciaram o regime de exercícios diários 24 horas após a lesão, porém com durações diferenciadas (G1 por 28 dias; G2 por 21 dias, G3 por 14 dias e G4 por sete dias). 0 exercício teve tempo e velocidade ajustados de acordo com o tempo de tratamento para cada grupo. Resultados: Por meio do cálculo do Índice Funcional do Ciático, os animais submetidos ao exercício apresentaram sinais de atraso na recuperação funcional da marcha, em comparação a animais controles. $\mathrm{Na}$ análise histológica dos nervos lesionados, observou-se que animais exercitados 
apresentaram sinais de preservação dos axônios no coto proximal e de degeneração no coto distal, e os animais exercitados por somente sete dias não apresentaram a mesma característica degenerativa no coto distal. A aplicação de exercícios ativos e sem carga em animais que sofreram axonotmese interfere negativamente no processo de recuperação funcional de alguns parâmetros da marcha. Conclusão: Apesar de o exercício ativo não ter interferido na manutenção da viabilidade neuronal nos sítios proximais à lesão, sua continuidade prejudicou a viabilidade dos cotos neurais distais, provável causa do atraso na recuperação funcional da marcha.

Palavras-chave: Regeneração nervosa. Exercício. Ratos. Índice funcional do ciático.

\section{Abstract}

Introduction: This study aimed to investigate if exercise in motorized wheel can affect the process of peripheral nerve regeneration in a rat model of axonotmesis. Material and methods: Forty-eight Wistar rats were divided equally into four groups containing six experimental and six control subjects. After proper training, the rats underwent right sciatic nerve axonotmesis. All groups started the exercises, in a daily basis, 24 hours after nerve injury, but at different durations (28 days for G1,21 days for G2, 14 days for G3 and seven days for G4). Both duration and speed of the exercises were gradually adjusted during the experiments. Results: The Sciatic Function Index revealed that exercised animals showed clear signs of delayed functional gait recovery. The histological analysis of injured nerves revealed that exercised animals showed signs of proximal stump preservation and degenerative signs in the distal stump. In other hand, exercised animals during seven days only showed axonal preservation in the distal stump. Conclusion: Based on these results, we believe that active exercises should be avoided, at least during the peripheral nerve regeneration process, i.e., during first 21 days after axonotmesis."

Keywords: Nerve regeneration. Exercise. Rats. Sciatic functional index.

\section{Introdução}

Lesão nervosa periférica (LNP) é o principal problema médico causado por acidentes com veículos automotores, trauma penetrante após incidentes com arma de fogo ou arma branca e por esmagamento ou estiramento do tecido nervoso após quedas (1-4). Pesquisas recentes têm estimado que aproximadamente $1 \%$ a $2 \%$ dos pacientes atendidos em centros de pronto socorro apresentam esse tipo de lesão $(5,6)$, o que representa uma das mais significantes formas de morbidade e incapacidade atualmente.

A LNP pode variar amplamente em extensão e severidade. Nervos periféricos contêm axônios motores mielinizados e axônios sensoriais mielinizados e não mielinizados. Os neurônios dos nervos periféricos regeneram seus axônios após a lesão e as células de Schwann dentro do envoltório nervoso desnervado apoiam a regeneração remielinizando apropriadamente os axônios $(7,8)$. Apesar dessa capacidade de reparo, os resultados funcionais após LNP em humanos são frequentemente desapontadores (9-11).
A perda funcional pode ser recuperada se os axônios lesados crescerem, alcançarem o coto distal e restabelecerem conexões funcionais com o alvo muscular apropriado. Isso representa o principal objetivo dos métodos que visam a auxiliar a regeneração nervosa periférica: assegurar o retorno mais eficaz possível dos níveis funcionais existentes anteriormente à lesão (12-14).

Atualmente, tem-se dado atenção ao desenvolvimento de abordagens não cirúrgicas para auxiliar o retorno funcional após a LNP. Essas surgem como métodos complementares às cirurgias e representam incremento importante para o processo de reinervação $(15,16)$.

Em uma recente revisão publicada no jornal British Medical Bulletin (15), os autores descrevem vários métodos não cirúrgicos no auxílio da recuperação funcional após LNP. Dentre as abordagens terapêuticas citadas, aparecem diversos recursos fisioterápicos.

Crescente corpo de evidências vem sendo obtido demonstrando os efeitos do exercício físico. Várias formas de exercício têm sido usadas durante a reabilitação de pacientes com LNP, para auxiliar na 
manutenção das propriedades musculares durante desnervação ou paralisia e para promover a recuperação funcional após a lesão ou doenças neurodegenerativas (17-22). Entretanto, falta, em todos esses trabalhos, padronização do protocolo utilizado, e os resultados obtidos são estritamente relacionados, à intensidade de exercício e ainda ao número e duração de sessões utilizadas.

\section{Materiais e métodos}

Os experimentos foram realizados no Laboratório de Fisioterapia Neurológica Experimental (LFNE) vinculado ao Departamento de Fisioterapia da Universidade Regional de Blumenau (FURB), e foram aprovados pela Comissão de Ética no Uso de Animais da Universidade Regional de Blumenau (CEUA-FURB, protocolo n. $017 / 08$ ).

\section{Grupos experimentais}

Foram utilizados 48 ratos Wistar machos adultos jovens (250-350 g), fornecidos pelo Biotério Central da FURB. Os animais foram acondicionados em gaiolas individuais, alojadas em ambiente com temperatura controlada $\left(24^{\circ} \mathrm{C}\right)$, ciclo claro-escuro de $12 \mathrm{~h}$ (foto período claro $=7 \mathrm{~h}-19 \mathrm{~h}$ ), e receberam água filtrada e alimentação ad libitum. Após período de sete dias de ambientação, todos os animais foram submetidos ao treinamento para familiarização com os procedimentos de coleta de dados e somente os animais tratados foram submetidos ao treinamento na roda de atividade por oito dias, $20 \mathrm{~min} /$ dia.

Os animais foram divididos em quatro grupos compostos por 12 animais cada (seis controle e seis tratados), todos submetidos à lesão por esmagamento do nervo ciático direito. Os animais denominados controle foram mantidos em suas gaiolas individuais, sem nenhum tipo de atividade adicional que pudesse caracterizar exercício físico semelhante ao aplicado com a roda motorizada. Todos os animais tratados iniciaram o regime diário de exercícios 24 horas após a lesão e cada grupo seguiu a seguinte programação: Grupo 1 - submetidos à atividade física durante 28 dias e sacrificados no $29^{\circ}$ dia pós-lesão; Grupo 2 - atividade física durante 21 dias e sacrificados no $22^{\circ}$ dia pós-lesão; Grupo 3 - atividade física durante 14 dias e sacrificados no $15^{\circ}$ dia pós-lesão; Grupo 4 - atividade física durante 7 dias e sacrificados no $8^{\circ}$ dia pós-lesão.

\section{Procedimento cirúrgico}

Para a realização da axonotmese do nervo ciático direito, os ratos foram anestesiados com $0,1 \mathrm{ml}$ (dose fixa) de xilazina (Rompum ${ }^{\circledR}$, Bayer) $+0,3 \mathrm{ml} / 100 \mathrm{~g}$ de cloridrato de cetamina (Ketalar ${ }^{\circledR}$, Parke Davis) por via intraperitoneal. Após a verificação do estado de consciência do animal (observado pela ausência de resposta motora ao pinçamento da cauda e das pregas interdigitais) foi feita a tricotomia local, seguida de uma incisão para exposição do nervo ciático e subsequente estrangulamento do nervo com uma pinça hemostática durante 30 segundos (23). Em seguida, foi realizada assepsia local com antiséptico tópico (Povidine ${ }^{\circledR}$ ) e o fechamento do campo cirúrgico com fio mononylon 4-0. Em seguida, os animais foram alojados nas mesmas condições pré-cirúrgicas.

\section{Programa de exercício}

Os animais tratados de cada grupo foram submetidos a 30 minutos diários de atividade na roda motorizada (Figura 1). Os animais eram inseridos dentro da roda, que começava a girar com a velocidade média de $3,5 \mathrm{~km} /$ hora. Essa velocidade foi previamente testada

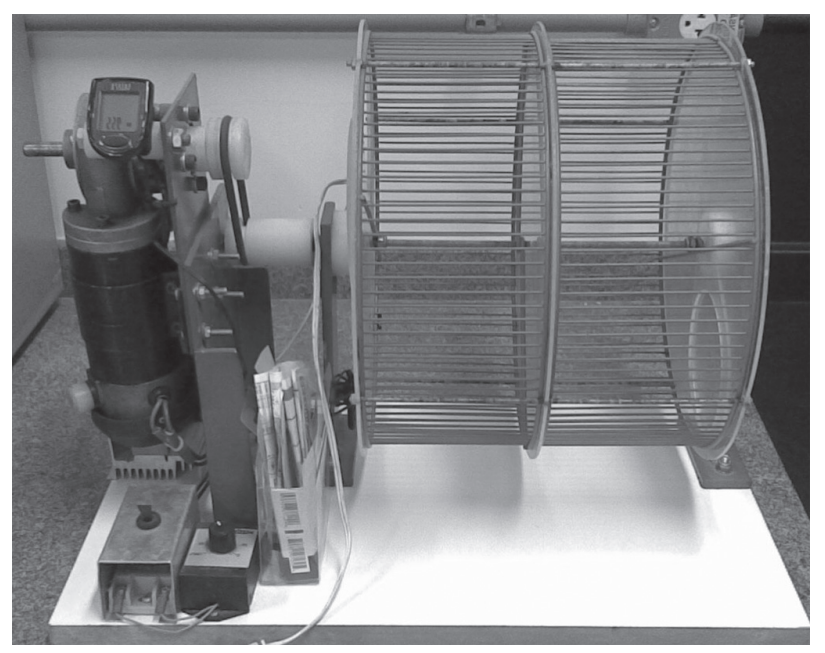

Figura 1 - Fotografia da roda de atividade construída mediante projeto próprio do Laboratório de Fisioterapia Neurológica Experimental

Fonte: Dados da pesquisa. 
com esses animais, no período de adaptação, e se mostrou a mais apropriada para o estudo.

\section{Coleta de dados funcionais}

Para a avaliação motora funcional, foi utilizado o Índice Funcional do Ciático (IFC) (24). Após a aquisição das imagens da face plantar das patas traseiras, a partir de um espelho em $45^{\circ}$ adaptado ao assoalho da pista de caminhada (Figuras 2B e 2C), as imagens foram analisadas com o programa ImageJ (rsbweb. nih.gov/ij) e os dados foram inseridos na fórmula que calcula o IFC. Valores próximos ou acima de zero caracterizam função motora preservada/recuperada, enquanto valores do IFC negativos indicam perda progressiva da função motora (25).

O número de avaliações variou conforme o desenho experimental para cada grupo, uma vez que os animais foram sacrificados ao fim do período de tratamento:

- Grupo 1: cinco avaliações: 24h, 7, 14, 21 e 28 dias após a lesão

- Grupo 2: quatro avaliações; 24h, 7, 14, e 21 dias após a lesão

- Grupo 3: três avaliações: 24h, 7 e 14 dias após a lesão

- Grupo 4: duas avaliações. 24h e 7 dias após a lesão.
Após a aquisição, os dados foram inseridos em planilha eletrônica que continha a fórmula referente ao cálculo do Índice Funcional do Ciático (Figura 2D).

\section{Coleta dos dados histológicos}

Após a última coleta dos dados funcionais, os animais foram eutanasiados e submetidos à perfusão transcardíaca com $\mathrm{NaCl} 0,9 \%$, seguido por formaldeído $10 \%$, para a extração do nervo ciático direito. 0 material coletado foi mantido no mesmo fixador por sete dias, incluído em parafina, fatiado em micrótomo (cortes seriados de $100 \mu \mathrm{m}$ ), corado com azul de toluidina e analisado em microscópio óptico. Foram observadas as características estruturais nervosas seguidas da contagem dos axônios conservados nos cotos, conforme sugerido por Oliveira et al. (26). Para a análise da porcentagem de mielinização da fibra, foi realizada a medição do diâmetro total (envoltório mielínico) e diâmetro axonal. Os dados do diâmetro axonal foram convertidos em porcentagem do diâmetro total axonal, então subtraídos de 100, e o resultado foi obtido em porcentagem.

\section{Análise estatística}

Os valores do IFC foram inseridos em planilha eletrônica conseguinte análise estatística por intermédio
(A)

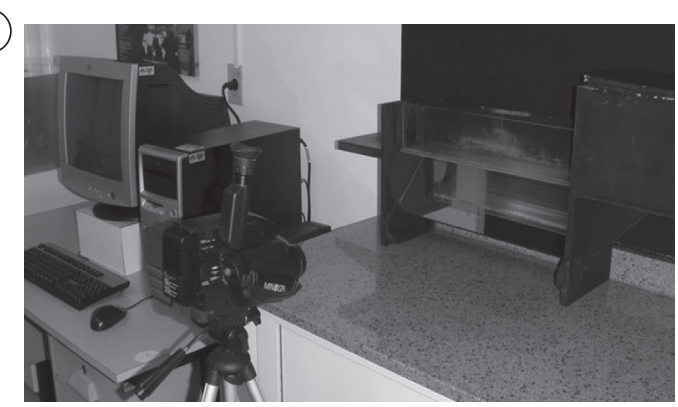

(D)

IFC $=-38,3\left(\frac{\text { EPL-NPL }}{N P L}\right)+109,5\left(\frac{\text { ETS-NTS }}{N T S}\right)+13,3\left(\frac{\text { EIT-NIT }}{\text { NIT }}\right)-8,8$
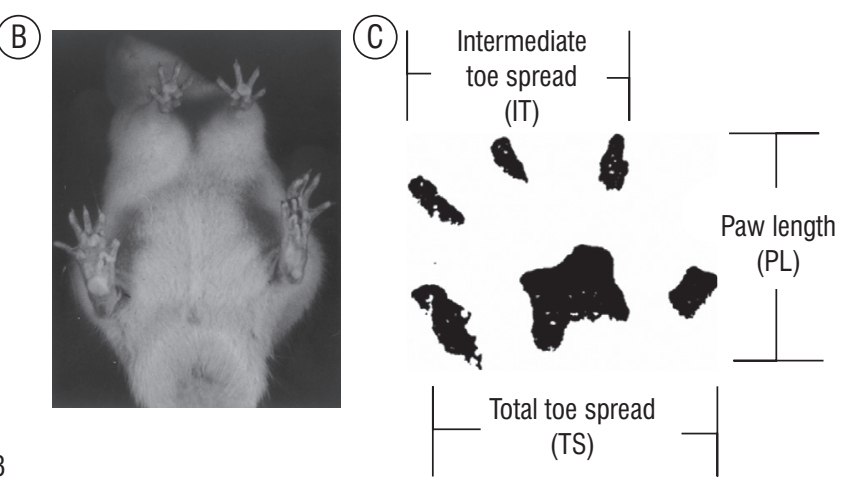

Figura 2 - Configuração do sistema (A) para a coleta das variáveis necessárias para o cálculo do IFC (C e D), onde: PL = comprimento da pegada (Print Length); TS = distância entre o primeiro e o quinto artelhos (Toe Spread); IT= distância entre segundo e quarto artelhos (Intermediate Toe spread); $\mathrm{N}=$ pata normal e $\mathrm{E}=$ pata experimental. C) Pata normal. D) Pata lesionada. (A: Laboratório LFNE; B, C e D: conforme referências 24 e 25).

Fonte: Dados da pesquisa. 
do programa Statistica 5.0 (StatSoft ${ }^{\circledR}$, Inc., 2004, data analysis software system, version 7). Os testes escolhidos foram: teste- $t$ de Student pareado para a determinação das variâncias dos dados, seguido pelo teste post-hoc de Tukey (determinação das diferenças significantes entre os grupos).

Os dados histológicos (contagem de fibras nervosas totais e porcentagem de mielinização) foram analisados estatisticamente conforme segue: teste de aderência à normalidade de Shapiro-Wilk, teste de homogeneidade das variâncias de Levene, ANOVA de uma via para a determinação das variâncias dos dados, acompanhada pelo teste post-hoc de "Duncan" (para determinação da diferença entre as médias dos diferentes grupos). 0 nível de significância estatística definido foi $\mathrm{p}<0,05$.

\section{Resultados}

Análise IFC

Quando comparados (teste " $t$ " pareado - controles versus experimentais) os IFCs coletados sete dias ( $\mathrm{W}=0,98632, \mathrm{p}=0,04424)$ após a lesão dos ratos exercitados diariamente $(-84,29 \pm 5,42)$ e dos respectivos controles $(-76,70 \pm 9,72)$, observou-se que o exercício retardou de forma significante o processo de recuperação funcional da marcha dos ratos exercitados. Enquanto, aos sete dias, os ratos sedentários obtiveram melhora de $12 \%$ em relação ao primeiro dia pós-lesão, os ratos exercitados obtiveram, aproximadamente, apenas 8\% de melhora.

Na segunda semana de experimentação (IFC coletado no 14ํo dia pós-lesão, $\mathrm{W}=0$,92323, $\mathrm{p}=0$,0657), os animais controle apresentaram média de IFC superior $(-62,32 \pm 14,13)$ à dos animais experimentais $(-74,50 \pm 8,02)$. 0 regime de exercícios ao $14^{\circ}$ dia continua sustentando a tendência de piora do quadro de recuperação da marcha, mostrando melhora de $29,9 \%$ nos animais controle, enquanto nos animais tratados a melhora corresponde a praticamente a metade (14,6\%) (Figura 3).

$\mathrm{Na}$ análise do IFC aos 21 dias $(\mathrm{W}=0,98520, \mathrm{p}=$ $0,96537)$, os grupos experimentais continuam acumulando resultados negativos de recuperação da marcha $(-21,54 \pm 5,23)$. Embora melhores que os valores referentes à semana anterior, permanecem significativamente inferiores aos do respectivo grupo controle $(-16.09 \pm 5,30)$ (Figura 3).
Aos 28 dias de investigação $(\mathrm{W}=0,97737, \mathrm{p}=$ 0,82846 ), somente 12 animais foram estudados, sendo seis animais controle $(\mathrm{N}=6)$ e seis animais experimentais $(\mathrm{N}=6)$. Os animais controle quase alcançaram positividade nos valores de IFC $(-0,662$ $\pm 7,59$ ), caracterizando recuperação funcional muito próxima da completa, enquanto os animais experimentais continuaram demonstrando um processo de recuperação funcional mais lento $(-4,642 \pm 4,70)$. Embora o número de animais exercitados até o $28^{\circ}$ dia seja reduzido, os dados seguem a mesma tendência das análises anteriores (7,14 e 21 dias) (Figura 3).

Merece ser destacado que no $1^{\circ}$ dia após a lesão, os valores de IFC próximos de -100 referem-se à perda funcional completa, e a similaridade de valores (controle $=-92,52 \pm 12,44$.; experimental $=-94,87 \pm 9,77$ ) indica que a lesão foi realizada corretamente (Figura 3).

Cabe ressaltar, também, que, ao serem comparados os valores de cada grupo, foi possível observar melhora funcional em todos eles. Entretanto, como foi demonstrado nas comparações semanais, os animais que foram exercitados mantiveram ritmo de recuperação funcional inferior ao dos animais que foram mantidos em suas gaiolas sem qualquer tipo de atividade que evidenciasse exercício semelhante ao imposto aos animais tratados.

\section{Análise histológica}

Em corte transversal do nervo ciático, foi possível analisar a densidade de axônios (numero de axônios

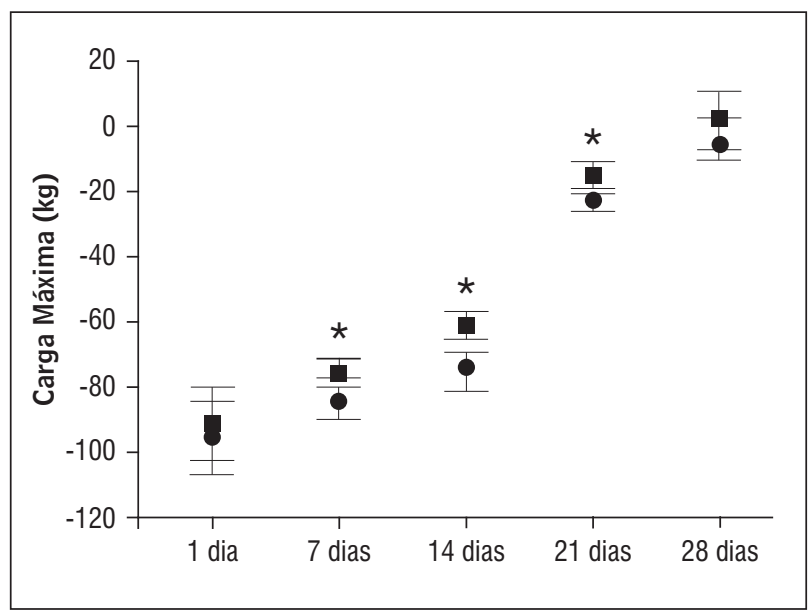

Figura 3- Valores de IFC dos grupos controle e experimentais (valores médios \pm desvio padrão). $\left({ }^{\star}\right)$ Diferenças significantes, $p<0,05$

Fonte: Dados da pesquisa. 
por $\mathrm{mm}^{2}$ ) e a porcentagem de mielinização, cujos dados brutos aderiram à condição de normalidade, conforme apontado pelo teste de Shapiro-Wilk (W = $0,85911, \mathrm{p}=0,7448$ ).

A análise histológica dos nervos dos grupos controle apontou resultados coerentes aos que foram encontrados com a análise funcional. Os dados revelaram que, apesar de não terem recebido nenhum tratamento, os animais apresentam regeneração espontânea de suas fibras nervosas ao longo do período estudado.

Conforme exposto na Figura 4, o exercício aparentemente não interferiu na manutenção da viabilidade dos axônios contidos tanto no coto proximal quanto no coto distal. A contagem axonal permaneceu praticamente estável ao longo do período de 28 dias de observação.

Para a contagem dos axônios contidos no coto proximal, os resultados dos animais tratados são semelhantes aos apresentados pelos animais controles (Figura 4). Para a contagem de axônios realizada no coto distal, entretanto, a Figura 5 demonstra que os animais exercitados sofreram perda significante dos axônios contidos no coto distal, quando comparados aos animais sedentários. Embora no sétimo dia não tenha sido possível observar diferença significante entre o grupo experimental e o seu controle, parece existir uma tendência de perda axonal no grupo experimental. A mesma tendência pode ser observada, também, no $28^{\circ}$ dia pós-axonotmese. Ainda na Figura 5, pode-se observar o efeito dramático de redução do número de axônios viáveis que ocorreu nos animais exercitados durante 14 dias $[F(1,4)=$ $67,85, p=0,002]$, e redução ainda mais acentuada aos 21 dias pós-axonotmese [F $(1,4)=12,51, \mathrm{p}=$ $0,001]$.

Além da quantidade de axônios presentes nos cotos proximal e distal, foi analisada a porcentagem de mielinização desses axônios. A Figura 6 apresenta vistas panorâmica e detalhada do coto distal de um animal exercitado (Figuras 6-A e 6-C) durante 21 dias e de seu respectivo controle (Figuras 6-B e 6-D). A Figura 6-C revela que o coto distal do animal sedentário manteve a mielinização dos seus axônios, ao passo que o animal exercitado durante 21 dias, além de ter sofrido redução numérica, também apresentou redução no índice de mielinização axonal (Figura 6-D).

\section{Discussão}

A lesão do nervo ciático por esmagamento é um modelo de axonotmese bem caracterizado $(23,26$, 27), que replica satisfatoriamente o processo conhecido por degeneração walleriana (28), o que facilita a rápida recuperação anatômica e funcional $(26,27)$, permitindo que as fibras remanescentes no coto proximal comecem a crescer e a invadir o coto distal para reinervar o músculo alvo $(7,29)$.

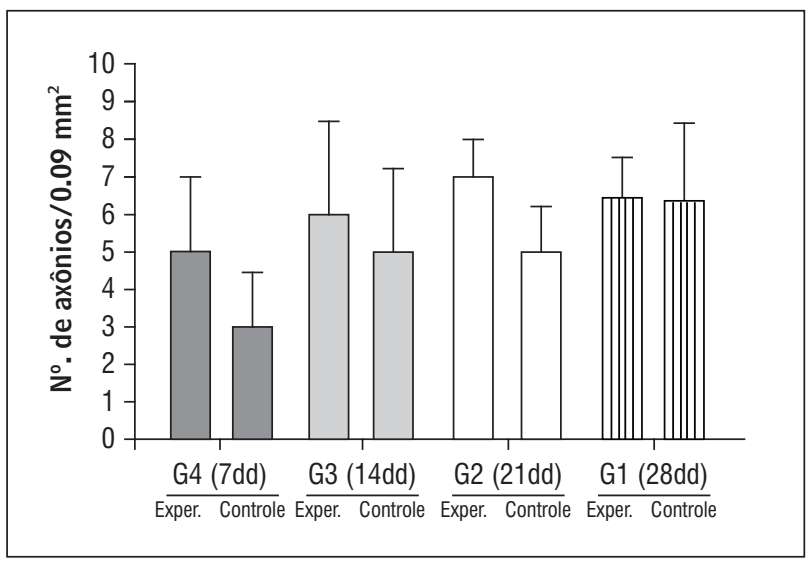

Figura 4 - Gráfico comparativo do número de axônios viáveis presentes no coto proximal dos grupos experimentais e controle

Fonte: Dados da pesquisa.

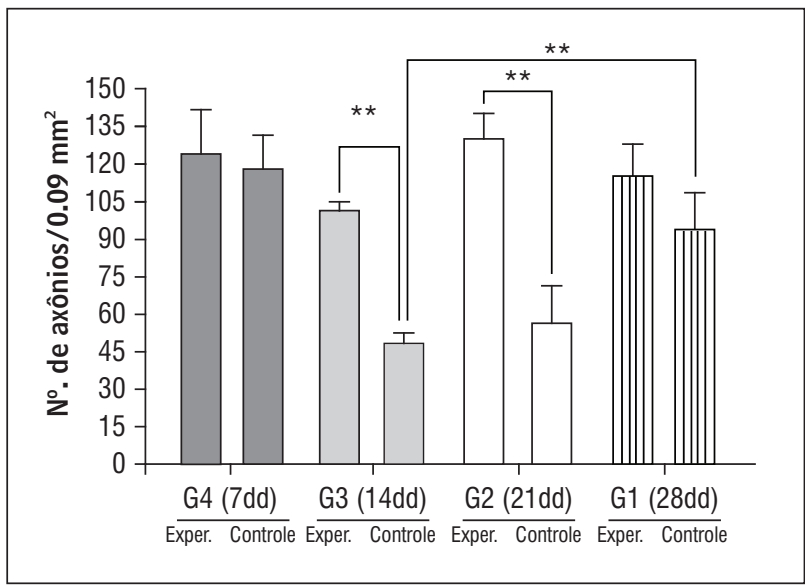

Figura 5 - Gráfico comparativo do número de axônios viáveis presentes no coto distal dos grupos experimentais e controle.

Fonte: Dados da pesquisa.

Legenda: $\left.{ }^{* \star}\right)$ Diferenças significantes, $p<0,01$. 
O período de regeneração nervosa, que ocorre logo após a lesão, revela diversas modificações morfológicas no nervo lesado (30), e um dos principais agentes desse cenário de mudanças são os macrófagos recrutados até o local da lesão durante a degeneração walleriana (31-33). Eles são responsáveis pela "limpeza" rápida, dentro de dois dias (34), do tubo endoneural distal, capacitando a entrada dos axônios em regeneração $(31,35-38)$. Além dos macrófagos, as células de Schwann também participam do processo regenerativo produzindo aumentos na expressão de fatores neurotróficos (38).

Todos esses processos começam a acontecer logo após a lesão da fibra nervosa e terminam quando o coto distal já está totalmente vazio e pronto para receber os axônios novos. Esse período de intensa ação inflamatória constitui momento essencial para a regeneração axonal e, portanto, qualquer variável inserida nesse contexto, e.g. exercício físico, pode interferir no destino da célula nervosa em regeneração $(39,40)$.

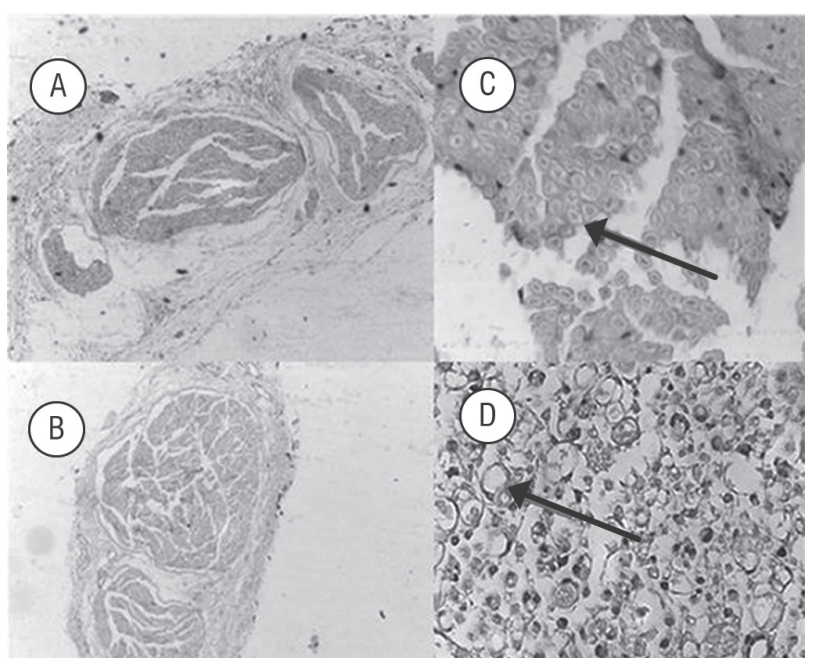

Figura 6 - Fotomicrografias de cotos distais e proximais de animais sedentários e exercitados. A) vista panorâmica do coto proximal do nervo ciático do grupo exercitado durante 21 dias; B) vista panorâmica do coto distal à lesão do grupo sedentário; C) porção proximal do nervo; seta indicando axônio mielinizado em animal sedentário; D) coto distal; seta indicando ausência do axônio, representando animal exercitado durante 21 dias ( $\mathrm{A} \mathrm{e}$ $B$ magnitude de 40x; C e D, magnitude de 400x)

Fonte: Dados da pesquisa.
Os resultados obtidos com a análise morfológica demonstram claramente que não houve alteração do número de axônios presentes no coto proximal do nervo ciático lesado em nenhum dos grupos analisados. Tanto os animais exercitados quanto os sedentários não apresentaram alterações morfológicas significantes no coto proximal ao longo das avaliações. Esses resultados são compatíveis com os descritos na literatura sobre as alterações que acontecem no coto proximal, somente poucos sofrem degeneração e raramente o próprio pericário é perdido $(30,41)$.

Assim como observado por outros autores $(3,7,8)$, as alterações morfológicas (redução no número de axônios viáveis, desmielinização e vacuolização) que encontramos se concentram no coto distal e acontecem somente nos animais que foram submetidos ao exercício físico. Dentre os diferentes animais controle de todos os grupos, podemos notar que o número de axônios presentes no coto distal se mantém uniforme ao longo das avaliações. Já entre os animais que foram tratados, os animais que foram submetidos ao exercício físico ao longo de 14 e 21 dias apresentaram menor número de axônios, tanto em relação ao seu respectivo grupo controle quanto ao número de axônios observado no coto distal dos animais exercitados por 7 ou 28 dias.

Os animais que não foram submetidos ao exercício físico mantiveram um padrão morfológico (número de axônios) ao longo do tempo. Dentre os animais tratados, o número de axônios é semelhante ao observados nos animais controle somente na primeira e na última avaliações. Podemos inferir que o exercício físico pode ter interferido de alguma forma na função dos macrófagos de preparação do coto distal para receber os axônios em regeneração.

A ação dos macrófagos é um passo essencial para a regeneração nervosa $(31,36,37)$. É, portanto, impossível que a ação dos macrófagos não tenha acontecido entre os animais controle. Aparentemente, essa ação deve ter acontecido antes dos sete primeiros dias após a lesão, uma vez que, na avaliação realizada nos animais que foram sacrificados ao oitavo dia, o número de axônios encontrados no coto distal se mantem uniforme nas demais avaliações.

0 exercício físico parece ter lentificado o processo de debridamento do coto distal, porque o número de axônios presentes no coto distal é similar entre os 
animais sacrificados no $8^{\circ}$ e no $28^{\circ}$ dia após a lesão, e menor nos animais que foram sacrificados no dia 15 e 22 após a lesão. Aparentemente, os macrófagos começaram sua ação na segunda semana e só deixaram o coto distal preparado ao fim da quarta semana, uma vez que podemos observar que o número de axônios começa similar ao observado para os animais controle, diminui e volta a subir somente ao fim do período de experimento.

A influência dos macrófagos sobre a regeneração nervosa parece ir além da sua capacidade fagocítica, e essas evidências se encaixam com os resultados que encontramos. Os macrófagos influenciam a expressão de um membro da família das neurotrofinas, o NGF (fator de crescimento neural). A maior taxa de expressão de NGF coincide com o pico de produção de macrófagos, que acontece, aproximadamente, entre 6 horas até 3 dias após a lesão (42).

Os fatores neurotróficos (FN) são expressos e liberados por tecidos alvo, células gliais, fibroblastos e macrófagos na vizinhança da célula nervosa (7). 0 conceito mais recente estabelece que FN são proteínas que regulam a sobrevivência, crescimento, plasticidade e síntese de proteínas utilizadas para funções especificas dos neurônios $(42,43)$, e diversas evidências têm demonstrado que a expressão de alguns FN é regulada pela atividade elétrica muscular, que normalmente é estimulada pela transmissão sináptica na junção neuromuscular $(44,45)$.

Nos animais exercitados, foi possível observar que sua evolução funcional segue o mesmo padrão apresentado pelos animais sedentários, mas nas avaliações realizadas nos dias 7, 14 e 21, os índices funcionais dos animais tratados ficam abaixo dos apresentados pelos grupos controle. Essa tendência pode ser um reflexo das alterações morfológicas encontradas no coto distal dos animais tratados durante esse período. Os animais que foram sacrificados no $15^{\circ}$ e $22^{\circ}$ dia, treinados por duas e três semanas, apresentaram menor número de axônios motores que os animais controle e, além disso, os animais tratados por três semanas ainda apresentaram menor porcentagem de mielinização dos axônios do coto distal que os demais grupos.

Esses resultados demonstram que a relação entre regeneração nervosa x rendimento funcional é uma via de mão dupla. 0 rendimento depende do número de axônios que se regeneram e a sobrevivência desses neurônios, por sua vez, depende de quão apropriada é a função que ele realiza: se o músculo não trabalha normalmente, o neurônio não é nutrido suficientemente e morre.

0 estudo da reciprocidade funcional entre as células pré e pós-sináptica da junção neuromuscular (fibra nervosa e fibra muscular, respectivamente) demonstra que a relação entre as duas células é bastante sensível às alterações de atividade que acontecem no alvo neuronal, isto é, no músculo. 0 aumento do número de contrações musculares seletivamente produzido por estimulação elétrica foi positivamente correlacionado com o aumento da expressão de RNAm para a neurotrofina NT-3. Entretanto, o aumento do nível da síntese de NT-3 somente foi observado ao segundo e terceiro dias, o que não aconteceu no sexto e no sétimo dias de estimulação, sugerindo que os efeitos da despolarização dependem do estágio do desenvolvimento em que se encontra a placa motora $(45,46)$.

Baseado nisso, suspeita-se que o protocolo de exercício físico utilizado pudesse ter interferido de forma negativa na liberação de FN e na atividade normal da junção neuromuscular. Outros autores também relataram resultados negativos e sugerem que o estresse relacionado à longa duração do exercício (47) e ao uso forçado do segmento corporal afetado (48) é a principal influência negativa à regeneração nervosa.

Em síntese, a aplicação de exercícios ativos e sem carga em animais que sofreram axonotmese interfere negativamente no processo de recuperação funcional de alguns parâmetros da marcha. Apesar de o exercício ativo não ter interferido na manutenção da viabilidade neuronal nos sítios proximais à lesão, sua continuidade prejudicou a viabilidade dos cotos neurais distais, provável causa do atraso na recuperação funcional da marcha.

\section{Referências}

1. Kouyoumdjian JA. Peripheral nerve injuries: a retrospective survey of 456 cases. Muscle Nerve. 2006;34(6):785-8. doi:10.1002/mus.20624.

2. Noble J, Munro CA, Prasad VS, Midha R. Analysis of upper and lower extremity peripheral nerve injuries in a population of patients with multiple injuries. J Trauma. 1998;45(1):116-22. doi:10.1097/00005373199807000-00025. 
3. Robinson LR. Traumatic injury to peripheral nerves. Muscle Nerve. 2000;23(6):863-73. doi:10.1002/(SICI)10974598(200006)23:6<863::AID-MUS4>3.0.CO;2-0.

4. Secer HI, Daneyemez M, Tehli O, Gonul E, Izci Y. The clinical, electrophysiologic, and surgical characteristics of peripheral nerve injuries caused by gunshot wounds in adults: a 40-year experience. Surg Neurol. 2008;69(2):143-52. doi:10.1016/j.surneu.2007.01.032.

5. Taylor CA, Braza D, Rice JB, Dillingham T. The incidence of peripheral nerve injury in extremity trauma. Am J Phys Med Rehabil. 2008;87(5):381-5. doi:10.1097/ PHM.0b013e31815e6370.

6. Eser F, Aktekin LA, Bodur H, Atan C. Etiological factors of traumatic peripheral nerve injuries. Neurol India. 2009;57(4):434-7. doi:10.4103/0028-3886.55614.

7. Fu SY, Gordon T. The cellular and molecular basis of peripheral nerve regeneration. Mol Neurobiol. 1997;14(1-2):67-116. doi:10.1007/BF02740621.

8. Zochodne DW. Neurobiology of peripheral nerve regeneration. Cambridge University Press: New York; 2008. doi:10.1017/CBO9780511541759.

9. Lundborg G, Rosén B. Hand function after nerve repair. Acta Physiol. 2007;189(2):207-17. doi:10.1111/ j.1748-1716.2006.01653.x.

10. Sulaiman OAR, Voda J, Gold BG, Gordon T. FK506 increases peripheral nerve regeneration after chronic axotomy but not after chronic Schwann cell denervation. Exp Neurol. 2002;175(1):127-37. doi:10.1006/ exnr.2002.7878.

11. Pfister BJ, Gordon T, Loverde JR, Kochar AS, Mackinnon SE, Cullen DK. Biomedical engineering strategies for peripheral nerve repair: surgical applications, state of the art, and future challenges. Crit Rev Bioeng. 2011;39(2):81-124. doi:10.1615/CritRevBiomedEng. v39.i2.20.

12. Cobianchi S, Marinelli S, Florenzano F, Pavone F, Luvisetto S. Short- but not long-lasting treadmill running reduces allodynia and improves functional recovery after peripheral nerve injury. Neuroscience. 2010;168(1):273-87. doi:10.1016/j.neuroscience.2010.03.035.

13. Gordon T, Chan KM, Sulaiman OAR, Udina E, Amirjani $\mathrm{N}$, Brushart TM. Accelerating axon growth to overcome limitations in functional recovery after peripheral nerve injury. Neurosurgery. 2009;65(4 Suppl):A132-44. doi:10.1227/01.NEU.0000335650.09473.D3.
14. Alluin O, Wittmann C, Marqueste T, Chabas JF, Garcia S, Lavaut MN, et al. Functional recovery after peripheral nerve injury and implantation of a collagen guide. Biomaterials. 2009;30(3):363-73. doi:10.1016/j.biomaterials.2008.09.043.

15. Albornoz PM, Delgado PJ, Forriol F, Maffulli N. Nonsurgical therapies for peripheral nerve injury. Br Med Bull. 2011;100:73-100.

16. Gordon T, Sulaiman O, Boyd JG. Experimental strategies to promote functional recovery after peripheral nerve injuries. J Peripher Nerv Syst. 2003;8(4):23650. doi:10.1111/j.1085-9489.2003.03029.x.

17. Sarikcioglu L, Oguz N. Exercise training and axonal regeneration after sciatic nerve injury. Int J Neurosci. 2001;109(3/4):173-7. doi:10.3109/00207450108986533.

18. Ilha J, Araujo RT, Malysz T, Hermel EE, Rigon P, Xavier LL, et al. Endurance and resistance exercise training programs elicit specific effects on sciatic nerve regeneration after experimental traumatic lesion in rats. Neurorehab Neural Repair. 2008;22(4):355-66. doi:10.1177/1545968307313502.

19. Asensio-Pinilla E, Udina E, Jaramillo J, Navarro X. Corresponding author contact information. Electrical stimulation combined with exercise increase axonal regeneration after peripheral nerve injury. Exp Neurol. 2009;219(1):258-65. doi:10.1016/j.expneurol.2009.05.034.

20. English AW, Wilhelm JC, Sabatier MJ. Enhancing recovery from peripheral nerve injury using treadmill training. Ann Anat. 2011;193(4):354-61. doi:10.1016/j. aanat.2011.02.013.

21. Udina E, Cobianchi S, Allodi I, Navarro X. Effects of activity-dependent strategies on regeneration and plasticity after peripheral nerve injuries. Ann Anat. 2011;123(4):347-53. doi:10.1016/j. aanat.2011.02.012.

22. Molteni R, Zheng JQ, Ying Z, Gómez-Pinilla F, Twiss JL. Voluntary exercise increases axonal regeneration from sensory neurons. Proc Natl Acad Sci. 2004;101(22):8473-8. doi:10.1073/ pnas.0401443101.

23. Bridge PM, Ball DJ, Mackinnon SE, Nakao Y, Brandt K, Daniel A, et al. Nerve crush injuries - a model for axonotmesis. Exp Neurol. 1994;127(2):284-90. doi:10.1006/exnr.1994.1104. 
24. de Medinacelli L, Freed WJ, Wyatt RJ. An index of the functional condition of sciatic nerve based measurements made from walking tracks. Exp Neurol. 1982;77(3):634-43. doi:10.1016/00144886(82)90234-5.

25. Costa J, Camargo VM, André ES. Desenvolvimento de um método de baixo custo para avaliação da marcha em ratos. Fisioter Mov. 2008;21(2):115-23. PMid:2183684.

26. Fawcett JW, Keynes RJ. Peripheral nerve regeneration. Annu Rev Neurosci. 1990;13:43-60. doi:10.1146/annurev.neuro.13.1.43.

27. Stoll G, Jander S, Meyers RR. Degeneration and regeneration of the peripheral nervous system: from Augustus Waller's observations to neuroinflammation. J Peripher Nerv Syst. 2002;7:13-27. doi:10.1046/ j.1529-8027.2002.02002.x.

28. Terenghi G. Peripheral nerve regeneration and neurotrophic factors. J Anat. 1999;194(Pt 1):1-14. doi:10.1046/j.1469-7580.1999.19410001.x.

29. Hokfelt T, Zhang X, Wiesenfeld-Hallin Z. Messenger plasticity in primary sensory neurons following axotomy and its functional implications. Trends Neurosci. 1994;17(1):22-30. doi:10.1016/01662236(94)90031-0.

30. Becker E, Bonni A. Cell cicle regulation of neuronal apoptosis and development and disease. Prog Neurobiol. 2004;72:1-25. doi:10.1016/j.pneurobio.2003.12.005.

31. Stoll G, Muller HW. Nerve injury, axonal degeneration and neural regeneration: basic insights. J Neurocytol. 1999;2:313-25.

32. Brück W. The role of macrophages in Wallerian degeneration. Brain Pathol. 1997;7(2):741-52. doi:10.1111/j.1750-3639.1997.tb01060.x.

33. Salegio EAA, Pollard AN, Smith M, Zhou XF. Macrophage presence is essential for the regeneration of ascending afferent fibres following a conditioning sciatic nerve lesion in adult rats. BMC Neurosci. 2011;12(11):1-13.

34. Toews AD, Barrett C, Morell P. Monocyte chemoattractant protein 1 is responsible for macrophage recruitment following injury to sciatic nerve. J Neurosci Res.1998,53(2):260-7. doi:10.1002/(SICI)1097-4547(19980715)53:2<260::AID-JNR15>3.0.CO;2-A.
35. Perry VH, Brown MC, Gordon S. The macrophage response to central and peripheral nerve injury: a possible role for macrophages in regeneration. J Exp Med. 1987;165(4):1218-23. doi:10.1084/ jem.165.4.1218.

36. Griffin JW, George R, Lobato C, Tyor WR, Yan LC, Glass JD. Macrophage responses and myelin clearance during Wallerian degeneration: relevance to immune-mediated demyelination. J Neuroimmunol. 1992;40(2-3):153-65. doi:10.1016/01655728(92)90129-9.

37. Perry VH, Brown MC, Andersson PB. Macrophage responses to central and peripheral nerve injury. Adv Neurol. 1993;59:309-14. PMid:3317065.

38. Lindholm D, Heumann R, Meyer M, Thoenen H. Interleukin-1regulated synthesis of nerve growth factor in non-neuronal cells of rat sciatic nerve. Nature. 1987;330(6149):658-9. doi:10.1038/330658a0.

39. Dodla MC, Bellamkonda RV. Peripheral nerve regeneration. In: Atala A, Lanza R, Thomson J, Nerem R. Principles of regenerative medicine. Oxford: Academic Press; 2008. p. 1049-62.

40. Richardson PM, Larry RS. Peripheral nerve regeneration: an overview. In: Binder MD, Hirokawa N, Windhorst U. Encyclopedia of neuroscience. Oxford: Academic Press; 2009. p. 557-60. doi:10.1016/B978008045046-9.00022-X.

41. Hall S. The response to injury in the peripheral nervous system. J Bone Joint Surg. 2005;87-B(10):130919. doi:10.1302/0301-620X.87B10.16700.

42. da Silva C. Fatores neurotróficos: estrutura, funções e aplicações clínicas. Atualiz Neuroc. 1995;1(1):1-20.

43. Bonhoeffer T. Neurotrophins and activity dependent development of the neocortex. Curr Opin Neurobiol. 1996;6(1):119-26. doi:10.1016/S09594388(96)80017-1.

44. Funakoshi H, Belluardo N, Arenas E, Yamamoto Y, Casabona A, Persson H, et al. Muscle-derived neurotrophin-4 as an activity-dependent trophic signal for adult motor neurons. Science. 1995;268(5216):14959. doi:10.1126/science.7770776.

45. Xie K, Wang T, Olafsson P, Mizuno K, Lu B. Activity-dependent expression of nt-3 in muscle cells in culture: implications in the development of neuromuscular junctions. J Neurosci. 1997;17(9):2947-58. 
46. Santos TS, André ES. Avaliação da marcha do rato após estimulação elétrica do músculo gastrocnêmio desnervado. Rev Neurocienc. 2007;15(2):120-4. PMid:9654553.

47. Amako M, Nemoto K. Influence of water immersion stress on peripheral nerve recovery in the rat. J Orthop Sci. 1998;3(1):32-41. doi:10.1007/s007760050019.
48. Humm JL, Kozlowski DA, James DC, Gotts JE, Schallert T. Use-dependent exacerbation of brain damage occurs during an early post-lesion vulnerable period. Brain Res. 1998;783(2):289-92. doi:10.1016/S0006 8993(97)01356-5.

Recebido: $13 / 10 / 2011$

Received: 10/13/2011

Aprovado: $11 / 05 / 2012$

Approved: 05/11/2012 